\title{
Role of ncRNAs in modulation of liver fibrosis by extracellular vesicles
}

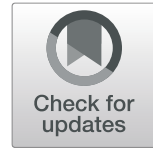

Giulia Chiabotto $^{1^{*}}$ (D) Giovanni Camussi ${ }^{1}$ and Stefania Bruno ${ }^{1,2}$

\begin{abstract}
Extracellular vesicles (EVs) are small membrane vesicles carrying bioactive lipids, proteins and nucleic acids of the cell of origin. In particular, EVs carry non-coding RNAs (ncRNAs) and the vesicle membrane may protect them from degradation. Once released within the extracellular space, EVs can transfer their cargo, including ncRNAs, to neighboring or distant cells, thus inducing phenotypical and functional changes that may be relevant in several physio-pathological conditions. This review provides an overview of the role of EV-carried ncRNAs in the modulation of liver fibrosis. In particular, we focused on EV-associated microRNAs (miRNAs) and long non-coding RNAs (IncRNAs) involved into the development of liver fibrosis and on the potential use of EV-associated ncRNAs as diagnostic and prognostic biomarkers of liver fibrosis.
\end{abstract}

Keywords: miRNA, IncRNA, non coding RNA, extracellular vesicles, exosomes, microvesicles, hepatic stellate cells, liver fibrosis

\section{Introduction}

Hepatic fibrosis is a reversible wound-healing response in the liver that occurs in response to a chronic liver damage, such as alcoholic liver disease (ALD), non-alcoholic steatohepatitis (NASH), hepatitis B virus (HBV) and hepatitis C virus $(\mathrm{HCV})$. If uncontrolled, progressive hepatic fibrosis can lead to cirrhosis, hepatocellular cancer (HCC) and endstage liver disease. Liver fibrosis is caused by a protracted imbalance in extracellular matrix (ECM) production and degradation $[1,2]$. The main source of ECM components in the development of liver fibrosis is provided by hepatic stellate cells (HSCs), which reside within an area between hepatocytes and sinusoidal endothelial cells, known as "space of Disse", and represent approximately $8 \%-14 \%$ of the cells in the normal liver [3, 4]. Following liver injury, HSCs undergo an activation process and transform from quiescent, vitamine A-storing cells into highly proliferative, myofibroblast-like cells, upregulating the synthesis of alpha1 type I collagen (Col1 $\alpha 1)$ and the expression of alpha

\footnotetext{
*Correspondence: giulia.chiabotto@unito.it

1 Department of Medical Sciences, University of Torino, Corso Dogliotti 14 10126 Torino, Italy

Full list of author information is available at the end of the article
}

smooth muscle actin ( $\alpha$-SMA), which confers contractility and promotes wound closure [1].

HSC activation is a critical event during liver fibrosis and is controlled by several cytokines and growth factors. A contribution to all stages of chronic liver disease progression, from initial liver injury through inflammation and fibrosis, is provided by transforming growth factor beta (TGF- $\beta$ ) [5]. Liver injury induces the release of active TGF- $\beta$ by damaged hepatocytes and inflammatory cells, thus upregulating the synthesis and release of several growth factors and cytokines involved in fibrogenesis, including platelet-derived growth factor (PDGF), connective tissue growth factor (CCN2), tumor necrosis factor alpha (TNF- $\alpha$ ) and various interleukins (ILs), such as IL-1 $\beta$, and IL-6 [6-10]. Moreover, increased levels of TGF- $\beta$ enhance hepatocyte destruction and mediate HSC activation, resulting in a wound-healing response that implies myofibroblasts generation and ECM deposition [5]. CCN2 is associated with the development of liver injury and its overexpression can lead to fibrosis aggravation [10]. TNF- $\alpha$ is involved in cholestasisinduced liver fibrosis [11]. IL-1 $\beta$ stimulates the synthesis of ECM [12], while IL-6 induces collagen synthesis and exacerbates hepatic inflammation [13].

(c) The Author(s). 2020 Open Access This article is licensed under a Creative Commons Attribution 4.0 International License, which permits use, sharing, adaptation, distribution and reproduction in any medium or format, as long as you give appropriate credit to the original author(s) and the source, provide a link to the Creative Commons licence, and indicate if changes were made. The images or other third party material in this article are included in the article's Creative Commons licence, unless indicated otherwise in a credit line to the material. If material is not included in the article's Creative Commons licence and your intended use is not permitted by statutory regulation or exceeds the permitted use, you will need to obtain permission directly from the copyright holder. To view a copy of this licence, visit http://creativecommons.org/licenses/by/4.0/. 
A growing body of research has shown that the activation of HSCs is orchestrated by a complex regulatory machinery, which also involves the dysregulation of several non-coding RNAs (ncRNAs) [14]. In the last decade, the pivotal role of microRNAs (miRNAs) and long ncRNAs (lncRNAs) in the activation of HSCs and progression of liver fibrosis has been intensively described [15-17]. Circulating levels of ncRNAs have been recognized as potential biomarker for various diseases, including liver fibrosis [18, 19]. An important example of a biological carrier that can transport abundant quantities of ncRNAs between cells and different tissues is that of the extracellular vesicle (EV). EVs are nanometer-sized, membrane-bound vesicles released by cells in both physiological and pathological conditions, which are mainly involved in cell-to-cell communication.

In this review, we will present the current knowledge about the role of EV-associated ncRNAs in the onset of liver fibrosis and we will discuss their potential use as biomarkers of hepatic fibrosis.

\section{Non-coding RNAs}

Recently, advances in RNA microarrays and nextgeneration sequencing of transcriptomes, have led to identification of several ncRNAs associated with a number of pathological conditions, including liver fibrosis. NcRNAs can be divided into two major classes of molecules, according to their transcript size: lncRNAs, with more than 200 nucleotides, and short ncRNAs which contain less than 200 nucleotides and include miRNAs, small interfering RNA, small nuclear RNA, small nucleolar RNA, tRNA-derived fragments and piwi-interacting RNA (piRNA).

\section{MicroRNAs (miRNAs)}

MiRNAs are approximately 22 nucleotides in length and were first described in 1993 by Ambros and colleagues [20]. They act as negative regulators of gene expression by promoting mRNA degradation or post-transcriptionally repressing mRNA translation [21-25]. Interestingly, miRNAs not only exert their function intracellularly, but are also exported from cells associated with Ago2 protein [26], bound to high-density lipoproteins [27], or incorporated in extracellular vesicles (EVs) such as exosomes [28] or apoptotic bodies [29]. Since miRNAs are involved in the coordination of several biological processes, such as cell proliferation and differentiation, migration, apoptosis and metabolism [22, 30-33], alteration in their expression profiles are frequently related to various pathological processes, including liver diseases [34, 35]. Several studies pointed out the role of circulating miRNAs as biomarkers of hepatic diseases. For instance, increased levels of circulating miR-122, one of the most abundant miRNA expressed in hepatocytes, have been identified in viral hepatitis [36-40], liver cirrhosis [41], drug-induced liver injury (DILI) [40, 42], HCC [43], ALD [40] and nonalcoholic fatty liver disease (NAFLD) [37, 44, 45]. Various miRNAs are implicated in the development of liver fibrosis. Since HSC activation is considered a critical initial step in hepatic fibrogenesis, interest has grown in the study of miRNAs that coordinate signaling pathways associated with myofibroblast activation, such as phosphatase and tensin homolog (PTEN)/Akt, epithelial-to-mesenchymal transition (EMT)/ERK1, nuclear factor kappa B (NF-kB) and peroxisome proliferator-activated receptor-gamma (PPAR $\gamma)$. One of the most studied anti-fibrogenic miRNAs is miR-29, which is downregulated by TGF- $\beta$ in activated HSCs [46]. When overexpressed, miR-29 leads to decreased HSC proliferation and increased HSC apoptosis, via inhibition of phosphoinositide-3-kinase (PI3K)/AKT pathway [47]. The downregulation of miR-155 has also been observed in activated HSCs from patients with cirrhosis and its enhanced expression results in HSC apoptosis with the inhibition of the EMT process and the ERK1 signaling pathway [48]. One of the predominantly upregulated miRNAs during fibrogenesis is miR-21, which is expressed in HSCs after PDGF stimulation and is associated with decreased expression of PTEN and consequent activation of Akt [49]. Similar to miR-21, miR-181b is involved in PTEN/Akt signaling pathway, being upregulated in HSCs by TGF- $\beta 1$ and promoting increased Col $1 \alpha 1$ synthesis and $\alpha$-SMA expression [50]. During HSC activation, an inverse correlation has been described between PPAR $\gamma$ and the expression of miR-33a, miR-34a and miR-34c. In fact, the inhibition of these three miRNAs increased PPAR $\gamma$ expression, which in turn decreased the expression of $\alpha$-SMA [51, 52]. Among the miRNAs involved in NF$\kappa B$ signaling pathway, miR-126, miR-221 and miR-222 are listed. MiR-126 overexpression in HSCs is associated with increased TGF- $\beta 1$ and type I collagen expression and re-

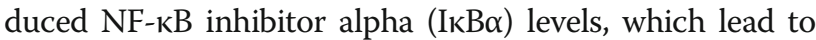
NF- $\kappa B$ upregulation [53]. The expression of miR-221 and miR-222 in activated HSCs is inhibited by IkB and enhanced by pro-fibrotic cytokines TGF- $\alpha$ and TNF- $\alpha$ [54].

\section{Long non-coding RNAs (IncRNAs)}

LncRNAs were first described in 2002 by Okazaki and colleagues [55], as a very heterogeneous population of ncRNA molecules with a size that varies from 200 nucleotides to 100 kilobases. As mRNAs, lncRNAs are transcribed by RNA polymerase II and then subjected to polyadenylation and splicing mechanisms [56]. Moreover, they can display a long open reading frame with more than 100 amino acids that usually characterizes protein-coding transcripts [57]. For these reasons, lncRNAs can be easily confused with protein-coding transcripts. However, unlike mRNAs, lncRNAs generally show low cellular expression levels, and exhibit tissue or 
cell type-specific expression [58]. Despite the lack of a common method for IncRNA identification, IncRNAs are usually classified into six categories, according to their genomic localization: sense lncRNAs, antisense lncRNAs, bidirectional or divergent lncRNAs, intronic lncRNAs, intergenic lncRNAs and enhancer lncRNAs [59, 60]. Since lncRNAs can be found both in the nuclear and in the cytoplasmic fraction, they can be also distinguished based on their cellular localization into signal, decoy, guide and scaffold lncRNAs [60, 61]. In the nucleus, IncRNAs exert their effects on chromatin architecture by interacting with chromatin remodeling proteins, thus regulating transcriptional activity of neighboring genes in "cis", or in "trans", away from their site of synthesis [62-66]. In the cytoplasm, IncRNAs may bind one or multiple miRNAs and act as miRNA precursors, or as miRNA sponges, also known as competing endogenous RNAs (ceRNAs), to either increase or reduce their expression and function [67]. LncRNAs are mainly regulators of development, pluripotency and proliferation, while some of them may function as oncogenes or tumor suppressors [68-71]. Moreover, lncRNA expression may be associated with patho-physiological conditions, including liver diseases and hepatic fibrosis. LncRNA-Hotair contributes to the progression of liver fibrosis through a miR-29b-mediated epigenetically modulation of PTEN expression [72] and by acting as ceRNA of miR-148b, which coordinates the DNA methyltransferase 1 (DNMT1)/ MEG3/p53 pathway in HSCs [73]. LncRNA-Hotair also recruits the polycomb repressing complex 2 (PRC2) to lncRNA-MEG3 promoter, thus contributing to MEG3 methylation-dependent downregulation, which has been reported in carbon tetrachloride $\left(\mathrm{CCl}_{4}\right)$-induced mouse liver fibrosis models, human fibrotic livers and in human activated HSCs [73, 74]. The TET3-mediated downregulation of lncRNA-HIF1A-AS1 leads to enhanced HSC proliferation and reduced apoptosis [75]. Both IncRNA-PVT1 and IncRNA-APTR promote the activation of HSCs and the progression of liver fibrosis [76, 77]. LncRNA-PVT1 contributes to EMT process by competitively binding miR-152 and silencing PTCH1 expression [76], while lncRNA-APTR increases cell cycle progression and proliferation of HSCs by inhibiting p21 expression [77]. On the other hand, lincRNA-p21 overexpression prevents liver fibrogenesis by promoting the upregulation of p21 [78] and by sponging miR-17-5p [79], thus suppressing the $\mathrm{Wnt} / \beta$-catenin pathway-mediated cell-cycle progression and proliferation in HSCs.

\section{Circular RNAs (circRNAs)}

Circular RNA (circRNA) is one of the latest areas of focus in the field of ncRNA research. It is a unique type of single-stranded lncRNA arranged in a closed loop structure, which is highly stable and resistant from RNA degrading enzymes $[80,81]$. In recent years, increased research has focused on the role of circRNAs as ceRNA or miRNA sponges, revealing their strong association with the development of various diseases and their possible use as diagnostic biomarkers [82-84]. The first report indicating an involvement of circRNAs in liver fibrosis comes from Chen and colleagues [85], who indentified differentially expressed circRNAs associated with HSC activation. In a model of radiation-induced HSC activation, they found 179 upregulated and 630 downregulated circRNAs compared with quiescent HSCs. In a $\mathrm{CCl}_{4}$-induced murine model of hepatic fibrosis, Zhou and colleagues have shown the differential expression of 69 circRNAs, of which 14 were upregulated and 55 downregulated in injured livers in respect to healthy controls [86]. In both experimental settings, bioinformatic analyses indicated that the dysregulated circRNAs may target miRNAs and proteins involved in the activation of HSCs, thus contributing to the development of liver fibrosis [85, 86]. Among the anti-fibrogenic circRNAs, hsa_circ_0007874 (also known as circ-MTO1) has proved to inhibit HSC activation and liver fibrogenesis by regulating miR-17-5p and Smad7 [87]. Instead, a positive correlation with liver fibrosis has been demonstrated for hsa_circ_0071410, since its inhibition attenuated irradiation-induced HSC activation by increasing the expression of miR-9-5p [85], mmu_circ 0000254 (also known as circ-PWWP2A) that contributed to HSC activation and proliferation by sponging miR-203 and miR-223 [88] and hsa_circ_100759 (also known as circ-4099) that increased $\mathrm{H}_{2} \mathrm{O}_{2}$-induced HSC injury by inhibiting miR-706 [89].

\section{Extracellular vesicles}

The term "EVs" refers to a heterogeneous population of lipid bilayer membrane-bound vesicles, originated from different sub-cellular compartments and released by cells into the environment in both physiological and pathological conditions. Due to their considerable heterogeneity and the lack of specific markers that could distinguish one type of vesicle from another, EVs are currently classified based on their size, biogenesis and secretion mechanisms [90, 91].

At present, the most considered EV populations are exosomes, ectosomes and apoptotic bodies. Exosomes are nano size vesicles $(30-100 \mathrm{~nm})$ with endosomal origin. They are released into the extracellular space following the inward and reverse budding of multivesicular bodies (MVBs)-membranes and their fusion with the cell surface [92]. This process, called exocytosis, is coordinated by the endosomal sorting complex required for transport (ESCRT) machinery that contributes to exosome formation by controlling ubiquitinated cargo selection (ESCRT-0), MVB intraluminal membrane budding (ESCRT-I and -II) and the scission from the endosomal membrane (ESCRT-III) [92-94]. The ESCRT machinery acts in coordination with auxiliary proteins involved in 
exosome biogenesis and secretion, such as hepatocyte growth factor-regulated tyrosine kinase substrate (HRS) $[95,96]$, tumor susceptibility gene 101 protein (TSG101) [96], apoptosis-linked gene-2 interacting protein $\mathrm{X}$ (ALIX) [94, 97] and vacuolar protein sorting-associated protein 4 (VPS4) [98]. However, exosome biogenesis could also occur through an ESCRT-independent mechanism [99]. This process is supported by tetraspanins (e.g. CD63, CD81, CD9), transmembrane proteins enriched in EVs, which are known to participate in cargo sorting and in exosome release [100-104]. Other proteins involved in the transport of MVBs to the plasma membrane for exosome release are small GTPases which mainly belong to the Ras [105] and Rab family [97, 106-109]. Finally, the synthesis of ceramide also plays a crucial role in exosome generation. In fact, the inhibition of specific enzymes involved in ceramide synthesis, such as neutral sphingomyelinase 2, has proved to reduce exosome release [110].

Ectosomes, also defined as shedding vesicles or microvesicles (MVs), include different populations of vesicles, the smallest with a diameter ranging from 50 to $200 \mathrm{~nm}$ and the largest with a diameter up to $1,000 \mathrm{~nm}$, some of them derived from pre-apoptotic cells. Unlike exosomes, ectosomes arise directly from plasma membrane budding and contain cytoplasmic constituents [111, 112]. The modifications in the plasma membrane curvature result from changes in lipid and protein interactions, which involve the arrestin domain-containing protein-1 (ARRDC1) and the late endosomal protein tumor susceptibility gene 101 (TSG101) [113]. The process of ectosomes vesiculation and release also relies on cytoskeleton rearrangements, controlled by the signaling cascade of Ras-related GTPase ADP-ribosylation factor 6 (ARF6) $[114,115]$. Finally, apoptotic bodies are EVs with a diameter ranging from 1,000 to $5,000 \mathrm{~nm}$ that are released by cells undergoing programmed death and may contain nuclear fragments and intact chromosomes [116].

In the last decades, EVs have emerged as important mediators of an evolutionarily well-preserved mechanism of intercellular communication [117]. In fact, following their release into the microenvironment, EVs can efficiently deliver selective patterns of proteins, bioactive lipids and nucleic acids $[118,119]$. The transfer of EV cargo into recipient cells can induce epigenetic and functional changes into target cells [120]. Several studies have shown that EVs are particularly enriched in different RNA species that, when transferred to recipient cells remained functional and can modify cellular behavior [28, 121-124]. The EV encapsulation efficiently protects RNA stability from the degrading activity of enzymes, like RNases, which are present in the extracellular space and in biological fluids $[121,125]$. Besides the main typical RNA species, like mRNAs, miRNAs and ribosomal RNAs, EVs may shuttle IncRNAs and small ncRNAs, such as tRNA-derived fragments, piRNA, small nucleolar RNA, Y-RNA and vault RNA [126-131]. Interestingly, EVs can also contain circular RNAs [132] and several mRNAs fragments enriched in the 3'-untranslated regions [133], suggesting their role as ceRNA to regulate translational activity of mRNAs in recipient cells.

EVs are abundant in all biological fluids, such as blood, urine, bile, amniotic fluid, synovial fluid, vitreous fluid, cerebrospinal fluid, breast milk, saliva, semen, tears [91]. However, most studies have focused on plasma-derived EVs, because they are easily accessible. Since EVs retain the molecular signature of the cell of origin, they can be exploited as biomarkers for diagnostic and prognostic purpose in patients with hepatic fibrosis.

\section{EVs in the onset of hepatic fibrosis}

Consistent with their role in intercellular communication, EVs are involved in different steps of the complex scenario of hepatic fibrosis development [134] (Figure 1). Progressive liver fibrosis usually arises from a recurrent epithelial injury that results in hepatocyte dysfunction and apoptosis, by an intrinsic intracellular stress-mediated pathway, or alternatively, through an extrinsic death receptormediated pathway $[135,136]$. Damaged hepatocytes can produce exosomes that contain proteins involved in the metabolism of lipoproteins, endogenous compounds, and xenobiotics. Interestingly, exosomes from injured hepatocytes are also enriched in proteins involved in cellular detoxification process, such as the cytochrome P450 family (CytP450s) [137]. Among these enzymes, CytP450 2E1 when overexpressed may promote hepatic apoptosis through a mechanism of oxidative stress [138]. Therefore, injured hepatocyte-derived exosomes containing CytP450s may participate in the development of liver fibrosis by promoting hepatocyte apoptosis. Hepatocytes treatment with $\mathrm{CCl}_{4}$ induces the release of exosomes able to increase the expression of IL-17A in $\gamma \delta \mathrm{T}$ cells, via toll-like receptor 3 [139]. In turn, proinflammatory IL-17-expressing $T$ cells modulate the production of TGF- $\beta 1$ in Kupffer cells and can directly activate ECM deposition by HSCs, thus enhancing liver fibrosis [140].

A relevant fibrogenic role in HSC activation is played by $\mathrm{CCN} 2$, an ECM-expressed cystein-rich protein that is produced in fibrotic liver tissue. CCN2 is involved in adhesion, migration, proliferation, survival and differentiation of HSCs and exhibits strong pro-fibrogenic properties [141]. CCN2 overexpression promotes the deposition of ECM, the development of fibrotic lesions and mediates TGF- $\beta 1$-dependent fibrotic pathways in HSCs $[142,143]$. Furthermore, exosomes derived from injured epithelial cells contain TGF- $\beta 1$ mRNA that can rapidly initiate myofibroblasts activation [144]. Recently, it has been demonstrated that CCN2 mRNA and protein are packaged into activated HSC-derived EVs and efficiently transferred into 


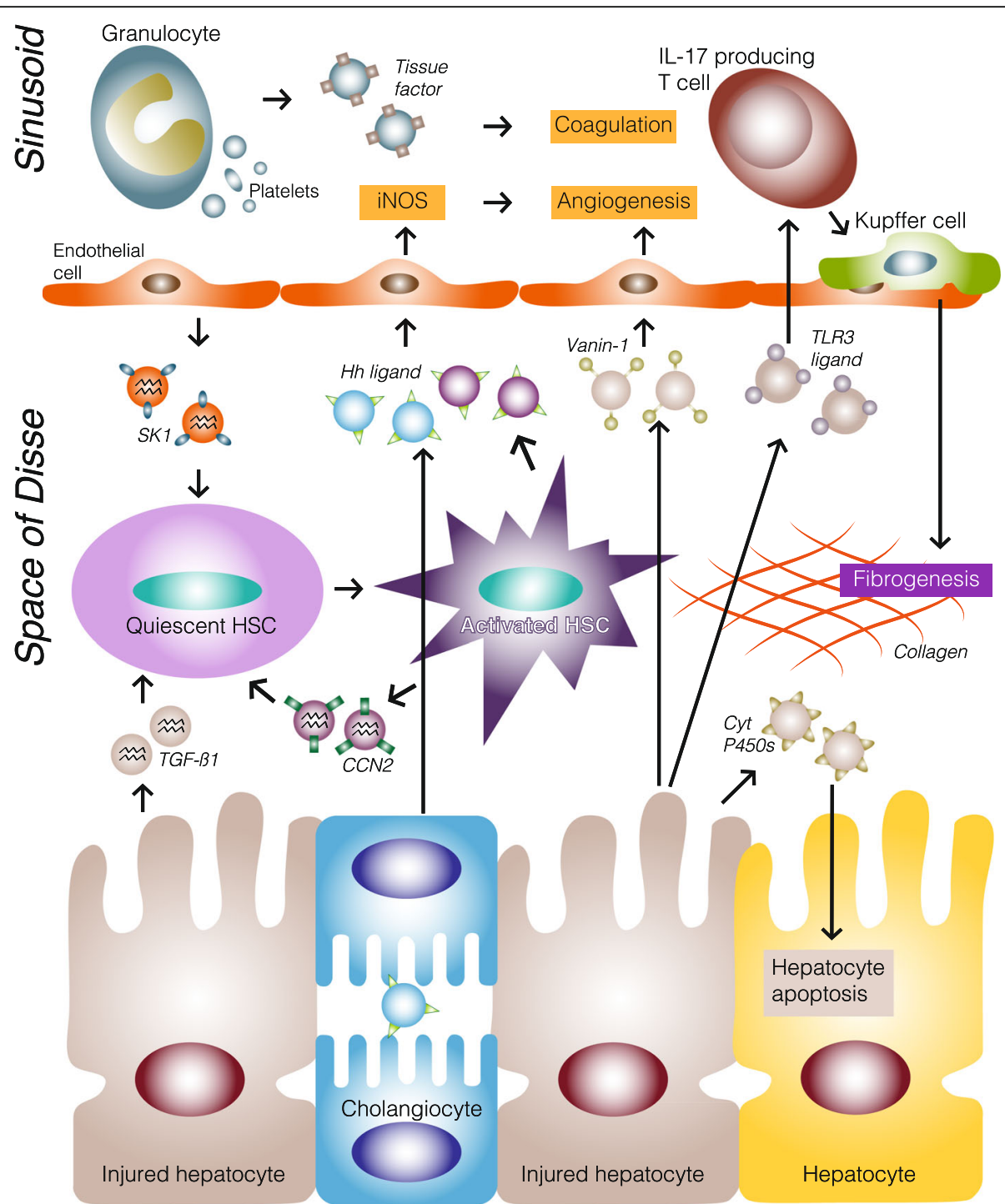

Fig. $1 \mathrm{EVs}$ in the onset of liver fibrosis. EVs of different origin promote fibrogenesis in the liver. Damaged hepatocytes release EVs containing CytP450s, which induces hepatocyte apoptosis, EVs containing TGF- $\beta 1$ mRNA, which induces HSC activation and EVs that increase IL-17A expression in T cells, via TLR3. In turn, IL-17-producing T cells induce the expression of TGF- $\beta 1$ in Kupffer cells, which prompt ECM deposition by HSCs. Coagulation cascade is activated by granulocyte and platelet-derived EVs which expose procoagulant proteins on their surface, such as tissue factor and phosphatidylserine. Angiogenesis is induced by hepatocyte-derived EVs that shuttle vanin-1 and EVs released by cholangiocytes and HSCs that contain Hh ligands, which increase the iNOS expression in endothelial cells. In turn, sinusoidal endothelial cells release EVs containing SK1 that prompt HSC migration. Activated HSCs release EVs containing CCN2 mRNA and protein that are taken up into quiescent HSCS, upregulating a-SMA expression. Abbreviations: CCN2, connective tissue growth factor; CytP450s, cytochrome P450 family; ECM, extracellular matrix; Hh ligand, Hedgehog ligand; HSC, hepatic stellate cell; iNOS, inducible nitric oxide synthase; SK1, sphingosine kinase 1; TGF- $\beta 1$, transforming growth factor $\beta 1$; TLR3, toll-like receptor 3 .

quiescent HSCs, resulting in the upregulation of CCN2 downstream targets, such as $\alpha$-SMA, and the activation of HSCs [145].

Another important aspect of HSC activation is the enhanced migration potential. During hepatic fibrosis, endothelial cells can release sphingosine kinase 1 (SK1)containing EVs that can prompt HSC migration [146]. The EV-induced HSC migration depends on EV adhesion, which consists in the binding of the EV-associated fibronectin with $\alpha \mathrm{V} \beta 1$ integrin on HSCs, followed by the dynamin-dependent internalization of EVs. As intrahepatic angiogenesis and sinusoidal remodeling promote fibrogenesis in the liver [147], HSC-derived EVs may contribute to fibrogenesis by modifying endothelial cell fate. It has been suggested that EVs derived from hepatocytes exposed to saturated, free fatty acid display a proangiogenic effect both in vitro and in vivo [148]. The release of EVs is regulated by the ectoenzyme 
pantetheinase, also called vanin-1, which is found primarily in liver, kidney and intestine, and has been associated with cell adherence and migration. High levels of hepatocyte-derived EVs associated with angiogenesis and early liver fibrosis were also detected in an in vivo model of dietary-induced steatohepatitis. The genetic inhibition of caspase3 effectively reduced circulating levels of hepatocytederived EVs and protected mice from angiogenesis and fibrosis [148]. Another important observation is that PDGF-stimulated HSCs and cholangiocytes release EVs enriched in hedgehog ligands that can alter the phenotype of hepatic sinusoidal endothelial cells [149]. In vivo experiments on rats subjected to bile duct ligation (BDL) have also confirmed that $\mathrm{EVs}$ isolated from plasma or bile contain hedgehog ligands, that can induce the expression of activation markers, such as inducible nitric oxide synthase and CD31, in hepatic sinusoidal endothelial cells [149]. All these findings highlight the role of EVs in the paracrine crosstalk between endothelium and HSCs in liver fibrosis.

Since hypercoagulation has proved to enhance liver fibrosis in chronic liver disease [150-152], another important EV contribution to hepatic fibrosis may be the activation of the coagulation cascade. It has been demonstrated that EVs derived from platelets or granulocytes in patients with sepsis have procoagulant properties and support thrombin generation, in proportion to the severity of the disseminated intravascular coagulopathy [153, 154]. Therefore, EVs contribute to liver fibrosis not only by promoting HSC migration and activation, but also by exhibiting proangiogenic and procoagulant effects that strengthen their pro-fibrogenic potential.

The contribution of EVs containing ncRNAs to liver fibrosis To date, a very large number of ncRNAs involved in the development of liver fibrosis have been described $[15,155$, 156]. In this chapter we will focus only on EV-associated miRNAs and lncRNAs and discriminate in particular profibrotic ncRNAs, which are upregulated in fibrogenesis, from anti-fibrotic ncRNAs, which are downregulated during liver fibrosis (Table 1).

\section{Pro-fibrotic ncRNAs shuttled by EVs}

Several studies have shown that EVs produced by hepatocytes exposed to lipotoxic stress can induce fibrotic HSC activation [161, 165, 180]. In particular, Feldstein and colleagues have demonstrated that hepatocytederived EVs contain several miRNAs that target PPAR$\gamma$, and identified miR-128-3p as a pro-fibrogenic miRNA that efficiently mediates EV effects on PPAR- $\gamma$ inhibition and HSC activation [161].

Exposure to alcohol and its metabolites, or hepatitis viral infection can also lead to hepatic injury and fibrogenesis. Recently, miR-19b and miR-92 expression has been found increased in exosomes isolated from activated HSCs and from the plasma of ALD cirrhotic patients [162]. These two miRNAs belong to the miR-17-92 cluster (miR-17a, -18a, $-19 a,-19 b,-20 a$, and -92$)$, mostly involved in the regulation of the TGF- $\beta$ pathway [181]. In the liver, miR-17-92 members coordinate different cellular pathways by targeting genes involved in lipid metabolism [182], inflammatory responses [183], EMT [184], cell proliferation [181, 185], apoptosis and necrosis [183]. Interestingly, miR-19 is present into EVs derived from $\mathrm{HCV}$-infected hepatocytes and is transported into HSCs, where it targets SOCS3 and activates the STAT3-mediated TGF- $\beta$ signaling pathway, leading to HSC activation and enhancing liver fibrosis [163]. Other miRNAs that have been detected in EVs released by HCV-infected hepatocytes are miR-122 [166] and miR-192 [172], two miRNAs expressed in large quantities in healthy hepatocytes [186]. In particular, the exosomal transfer of miR-192 into HSCs induces their fibrotic activation, while treatment of HSCs with miR-192 inhibitor can effectively revert the myofibroblast transdifferentiation of HSCs [172].

The increase in lncRNA-MALAT1 expression is associated with inflammation and fibrosis in NASH patients [187] and is negatively correlated with miR-101b expression levels in fibrotic livers and in activated HSCs [188]. Recently, it has been observed that MALAT1 is contained in exosomes released by arsenite-treated hepatic cells and is transported into HSCs, where it promotes their activation through miR-26b regulation of Coll $\alpha 2$ expression [160]. Another lncRNA associated with the progression of liver fibrosis is the lncRNA-H19, which acts as ceRNA of let-7 family upregulating its target high-mobility group AT-hook 2 (HMGA2) and causing cholangiocyte proliferation [157]. The release of exosomal lncRNA-H19 by cholangiocytes is associated with HSC activation and cholestatic liver injury (CLI) $[158,159]$. Under cholestatic conditions, the taurocholate acid and estrogeninduced activation of ERK1/2 signaling pathway upregulates lncRNA-H19 in cholangiocytes and in exosomes released by these cells [159, 189]. Exosomal lncRNA-H19 is delivered to hepatocytes, where it downregulates the small heterodimer partner (SHP), which is involved in the regulation of bile acid homeostasis [190]. Moreover, IncRNA-H19-enriched exosomes can be taken up by HSCs both in vitro and in vivo, resulting in HSC proliferation and activation with the upregulation of pro-fibrotic gene expression [158].

\section{Anti-fibrotic ncRNAs shuttled by EVs}

Increasing evidence has pointed out the key role of miR30a in myocardial [191] and peritoneal fibrosis [192] and its contribution to the suppression of EMT process during HSC activation [193]. It has been observed that miR-30a is downregulated both in activated HSCs and in exosomes derived from activated HSCs [178]. On the 
Table 1 EV-associated ncRNAs in liver fibrosis

\begin{tabular}{|c|c|c|c|c|c|c|}
\hline & ncRNAs & $\begin{array}{l}\text { EV expression in } \\
\text { hepatic fibrosis }\end{array}$ & Fibrosis model & $\begin{array}{l}\text { Target } \\
\text { genes in } \\
\text { fibrosis }\end{array}$ & Functions & Citations \\
\hline \multirow{4}{*}{ PRO-FIBROTIC } & IncRNA-H19 & $\begin{array}{l}\uparrow \text { in EVs from damaged } \\
\text { cholangiocytes }\end{array}$ & CLI & HMGA2, SHP & $\begin{array}{l}\text { HSC activation, proliferation, } \\
\text { differentiation, Biomarker of } \\
\text { hepatic fibrosis }\end{array}$ & [157-159] \\
\hline & IncRNA-MALAT1 & $\begin{array}{l}\uparrow \text { in EVs from damaged } \\
\text { hepatocytes }\end{array}$ & DILI & Col1a2, via miR-26b & $\begin{array}{l}\text { HSC activation, Biomarker of } \\
\text { hepatic fibrosis }\end{array}$ & [160] \\
\hline & miR-128-3p & $\begin{array}{l}\uparrow \text { in EVs from damaged } \\
\text { hepatocytes }\end{array}$ & NAFLD & PPAR- $\gamma$ & HSC activation & [161] \\
\hline & miR-17-92 cluster & $\begin{array}{l}\uparrow \text { in EVs from activated } \\
\text { HSCs, damaged } \\
\text { hepatocytes and plasma }\end{array}$ & ALD, HCV hepatitis & $\begin{array}{l}\text { SOCS3, TGF- } \beta \text { signaling } \\
\text { pathway }\end{array}$ & $\begin{array}{l}\text { HSC activation, EMT, lipid } \\
\text { metabolism, inflammatory } \\
\text { responses, proliferation, } \\
\text { apoptosis, necrosis }\end{array}$ & {$[162,163]$} \\
\hline \multirow{10}{*}{ ANTI-FIBROTIC } & let-7s & $\begin{array}{l}\downarrow \text { in EVs from activated } \\
\text { HSCs and plasma }\end{array}$ & HCV hepatitis & $\begin{array}{l}\text { TGF- } \beta \text { signaling } \\
\text { pathway }\end{array}$ & Biomarker of hepatic fibrosis & [164] \\
\hline & miR-122 & $\begin{array}{l}\uparrow \text { in EVs from damaged } \\
\text { hepatocytes } \uparrow \text { in plasma } \\
\text { EVs } \\
\uparrow \text { in EVs from engineered } \\
\text { ADSCs }\end{array}$ & $\begin{array}{l}\text { In vitro HSC activation, } \\
\text { NASH, NAFLD, ALD, } \\
\text { DILI, } \\
\text { HCV hepatitis }\end{array}$ & CCNG1, IGF1R, P4HA1 & $\begin{array}{l}\text { Survival, proliferation, EMT, } \\
\text { fibrosis suppression } \\
\text { biomarker of hepatic fibrosis }\end{array}$ & {$[161,165-170]$} \\
\hline & miR-181-5p & $\begin{array}{l}\uparrow \text { in EVs from engineered } \\
\mathrm{ADSCS}\end{array}$ & $\begin{array}{l}\text { In vitro HSC activation, } \\
\text { NASH }\end{array}$ & STAT3, BCl-2, Beclin1 & Fibrosis suppression & [171] \\
\hline & miR-192 & $\uparrow$ in plasma EVs & $\begin{array}{l}\text { NAFLD, } \\
\text { HCV hepatitis }\end{array}$ & & $\begin{array}{l}\text { HSC activation, biomarker of } \\
\text { hepatic fibrosis }\end{array}$ & {$[161,165,172]$} \\
\hline & miR-199a-5p & $\begin{array}{l}\uparrow \text { in EVs from quiescent } \\
\mathrm{HSCS}\end{array}$ & In vitro HSC activation & CCN2 & $\begin{array}{l}\text { Adhesion, migration, } \\
\text { proliferation survival and } \\
\text { differentiation of HSCs }\end{array}$ & [173] \\
\hline & $\operatorname{miR}-214$ & $\begin{array}{l}\uparrow \text { in EVs from quiescent } \\
\text { HSCS, } \downarrow \text { in EVs from } \\
\text { activated HSCs and } \\
\text { plasma }\end{array}$ & In vitro HSC activation & CCN2 & $\begin{array}{l}\text { Adhesion, migration, } \\
\text { proliferation survival and } \\
\text { differentiation of } \mathrm{HSCs}, \\
\text { Biomarker of hepatic fibrosis }\end{array}$ & {$[174,175]$} \\
\hline & $\begin{array}{l}\operatorname{miR}-22-3 p,-26 a-5 p \\
-27 b-3 p,-302-3 p \\
-486-5 p,-92 a-3 p \\
-92 b-3 p\end{array}$ & $\uparrow$ in EVs from iPSCs, & $\begin{array}{l}\text { In vitro HSC activation, } \\
\text { NASH, BDL }\end{array}$ & $\begin{array}{l}\text { TGF- } \beta \text { signaling } \\
\text { pathway }\end{array}$ & Fibrosis suppression & [176] \\
\hline & miR-223 & $\begin{array}{l}\uparrow \text { in EVs from engineered } \\
\text { BM-MSCs }\end{array}$ & $\mathrm{AlH}$ & NLRP3, caspase-1 & Fibrosis suppression & [177] \\
\hline & miR-30a & $\begin{array}{l}\downarrow \text { in EVs from activated } \\
\text { HSCs }\end{array}$ & BDL & Beclin1 & EMT, autophagy & [178] \\
\hline & $\begin{array}{l}\operatorname{miR}-34 c,-151-3 p \\
-483-5 p,-532-5 p\end{array}$ & $\downarrow$ in serum EVs & NASH & $\begin{array}{l}\text { PDGF, TIMP2, SMAD3 } \\
\text { (predicted) }\end{array}$ & $\begin{array}{l}\text { fibrosis suppression, } \\
\text { biomarkers of } \\
\text { hepatic fibrosis }\end{array}$ & [179] \\
\hline
\end{tabular}

other hand, miR-30a overexpression ameliorates hepatic fibrosis by suppressing Beclin1-mediated autophagy and increasing lipid accumulation in HSCs and in murine fibrotic liver tissues after BDL [178].

The association between the downregulation of miR214 and miR-199a-5p and the increase of CCN2 expression in fibrotic livers and in cultured activated primary mouse HSCs has been described by Brigstock and colleagues $[173,174]$. They observed that quiescent HSCs release EVs that inhibit the activation of HSCs and attenuate fibrosis. Next, they demonstrated that exosomes derived from quiescent HSCs were enriched in miR-214 and miR-199a-5p, which both specifically bind to the 3 'untranslated region of $\mathrm{CCN} 2$, thus reducing the expression levels of CCN2 and of its downstream targets Col1 $\alpha 1$ and $\alpha$-SMA $[173,174]$. A Twist1-miR-214-CCN2 axis has also been identified in HSCs. EVs secreted by quiescent HSCs contained high levels of Twist1, which can induce miR-214 expression in activated HSCs, thus suppressing CCN2 expression levels and reverting HSCs to a more quiescent phenotype [175].

Recently, it has been shown that stem cell-derived ncRNA-containing EVs may exert an anti-fibrogenic effect. In particular, mesenchymal stromal cells (MSCs) efficiently support the repair and regeneration of injured tissues through the release of paracrine factors, such as EVs [194]. Several papers have explained the therapeutic effects of MSC-EVs in preclinical models of hepatic 
fibrosis [195, 196]. Besides the proteins and transcripts shuttled by stem cell-derived EVs, their ncRNA cargo has proved to modulate HSC biology, thus reverting liver fibrosis. Feldstein and colleagues have demonstrated that human induced pluripotent stem cell (iPSC)-derived EVs can effectively deliver anti-fibrogenic miRNAs into HSCs, thus reducing their activation and attenuating liver fibrosis [176]. By performing genomic analysis of iPSC-EV miRNA cargo, they identified 22 highly expressed miRNAs, among which miR-22-3p, miR-26a-5p, miR-27b-3p, miR-302-3p, miR-486-5p, miR-92a-3p and miR-92b-3p all display potential anti-fibrotic properties [176].

Recent advances in nanomedicine, allowed the generation of engineered EVs that may be more effective than naïve EVs against liver fibrosis $[167,171,177]$. Lou and colleagues have demonstrated that lentiviral-induced miR-122 expression in adipose tissue-derived MSCs (ADSCs) increased their therapeutic effect in hepatic fibrosis [167]. The EVmediated transfer of miR-122 from ADSCs resulted in the cell cycle arrest of HSCs and the downregulation of miR122-target genes involved in HSC proliferation and collagen maturation, such as prolyl-4-hydroxylase a1 (P4HA1), insulin-like growth factor receptor 1 (IGF1R) and cyclin G1 (CCNG1) [167]. The transient overexpression of miR-181$5 p$ in ADSCs represents another therapeutic strategy against liver fibrosis [171]. As for miR-122, miR-181-5p can be delivered by ADSC-EVs to HSCs, where it modulates the fibrosis-associated STAT3/Bcl-2/Beclin1 pathway, thus reducing TGF- $\beta 1$ expression and inducing autophagy in HSCs. Moreover, the in vivo administration of miR-181-5poverexpressing ADSC-EVs attenuated liver injury and reduced liver expression of pro-fibrotic genes, such as type I collagen, $\alpha$-SMA, vimentin and fibronectin [171]. In a model of autoimmune hepatitis (AIH), the lentivirus-mediated upregulation of miR-223 in bone marrow (BM)-derived MSCs improved the cytoprotective effect of BM-MSC-EVs, both in vitro and in vivo [177]. The engineered EVs prompted the increase of miR-223 levels in the liver, which results in the improvement of liver function and the reduction of inflammation and hepatocyte apoptosis, through the downregulation of miR-223-target genes NLRP3 and caspase-1. However, the specific removal of miR-223 from BM-MSCs completely abrogated the therapeutic effects of BM-MSCEVs [177].

Our group has demonstrated that EVs released by human liver stem cells (HLSCs) can reduce fibrosis in a murine model of NASH [197]. Proteomic analyses performed on HLSC-EV cargo revealed several anti-inflammatory proteins that may contribute to the attenuation of fibrosis. However, the role of HLSC-EVs in the reversal of hepatic fibrosis may be also related to the EV-mediated transfer of specific mRNAs and ncRNAs from HLSCs to injured hepatocytes and activated HSCs. Our previous results on two different in vivo models of chronic kidney diseases have shown that the administration of HLSC-EVs reduced the expression of pro-fibrotic genes $\alpha$-SMA, Col $1 \alpha 1$, and TGF- $\beta 1$ [198, 199]. Moreover, we have pointed out a correlation between the anti-fibrotic effect of HLSC-EVs and their ncRNA cargo, which includes specific anti-fibrotic miRNAs, such as miR-29a, miR-30a and the the let-7 family, that are known to contribute to the reversal of hepatic fibrosis [199].

\section{EVs-shuttled ncRNAs as biomarkers of liver fibrosis}

In addition to information exchange, interest has grown in the role of ncRNA associated with EVs as biomarkers in liver diseases and hepatic fibrosis [18, 200, 201].

Research by the group of Brigstock and colleagues has demonstrated that reduced circulating levels of exosomal miR-214 in mice with liver fibrosis reflect the fibrosisinduced modifications in the liver [175]. Moreover, the same group identified decreased levels of miR-34c, miR151-3p, miR-483-5p and miR-532-5p in serum EVs derived from fibrotic mice treated with $\mathrm{CCl}_{4}$ and from human patients with liver fibrosis [179]. All of these miRNAs were shown to cooperatively suppress HSC activation, but predictive computational analysis did not pinpoint classical HSC activation markers CCN2, $\alpha$-SMA or Col $1 \alpha 1$ as direct targets of these miRNAs, suggesting that they are likely secondary downstream targets. In particular, the overexpression of miR-483-5p counteracts liver fibrosis by suppressing tissue inhibitor of metalloprotease-2 (TIMP2) and PDGF- $\beta$ [202], while miR-532-5p is predicted to target SMAD3, which modulates CCN2 transcription in HSCs, thus regulating liver fibrogenesis [203].

In the context of chronic hepatitis, the progression of hepatic fibrosis has been related to EVs produced by HCV-infected hepatocytes $[163,164]$. In a cohort of patients with chronic hepatitis $\mathrm{C}$, Matsuura and colleagues have observed a negative correlation between levels of circulating or EV-shuttled let-7 family and the severity of hepatic fibrosis. Furthermore, pathway analysis of target genes of let- 7 suggested that low levels of let-7 in EVs may be related to hepatic fibrogenesis through the activation of TGF- $\beta$ signaling in HSCs [164].

The characterization of EVs into the bloodstream of an experimental NAFLD model identified both exosomes and MVs enriched in miR-122 and miR-192 [45]. Diet-induced liver damage led to the downregulation of miR-122 in activated HSCs [204, 205] and in injured hepatocytes [168]. Simultaneously, high miR-122 circulating levels have been detected both in the EV and in the protein-rich (EV-free) serum fractions [168]. Interestingly, increased circulating levels of EV-associated miR-122 were also detected in the plasma of subjects with alcoholic hepatitis [169, 170]. Moreover, during NAFLD progression, levels of miR-122 and miR-192 increased in circulating EVs while decreased in liver cells [165]. The release of these two miRNAs from 
damaged hepatocytes in EVs during NAFLD progression may be a possible explanation of miR-122 and miR-192 increased expression in circulating EVs from advanced stage NAFLD patients compared to those from early stage NAFLD patients. These results suggest the role of EVassociated miR-122 and miR-192 as biomarkers of hepatic fibrosis that can be used to monitor and discriminate the stage of the disease in patients with chronic liver injury.

The analysis of circulating EVs from subjects exposed to arsenite has pointed out a correlation between the progression of liver fibrosis and the increase of IncRNA-MALAT1 levels in circulating exosomes [160]. This observation encourages the use of EV-associated lncRNA-MALAT1 as a possible biomarker of hepatic fibrosis caused by arsenicosis. Finally, a correlation between serum levels of exosomeassociated lncRNA-H19 and the severity of cholestatic liver fibrosis has been observed in both mouse CLI models and in human patients with different types of cholestatic liver disease [157-159]. In particular, the co-expression of IncRNA-H19 and CK19 indicates that these exosomes are mainly released by damaged cholangiocytes during cirrhosis and explain their increase during the progression of hepatic fibrosis.

\section{Conclusions}

NcRNAs were proved to have a pathogenic involvement in the development of liver fibrosis, as well as a diagnostic potential. Several ncRNAs are carried by EVs and are protected by their lipid membrane bilayer from degradation. Moreover, EVs may deliver ncRNAs at distance and local sites, thus influencing several physiological and pathological processes. EVs have proved to be active mediators of intercellular communication in a number of pathological conditions, including liver fibrosis. The damaged hepatocytes produce EVs that act in a paracrine manner to regulate key processes of hepatic fibrosis, such as HSC activation, angiogenesis and coagulation. In turn, EVs secreted by circulating cells and sinusoidal epithelial cells modify liver microenvironment, thus influencing the progression of liver fibrosis. Analysis of the EVs cargo, in particular ncRNAs, may provide further insight in the epigenetic modulation of genes and pathways related to hepatic fibrogenesis. Moreover, several studies have shown that EVs are promising biomarkers for diagnostic and prognostic purposes in patients with chronic liver diseases, as they are implicated in many stages of fibrosis development and progression.

In the future, one may envisage the use of EVs to deliver therapeutic molecules to enhance liver regeneration. Preliminary studies have also shown that native EVs carrying anti-fibrotic ncRNAs may have a therapeutic potential. In particular, MSC-derived EVs have proved to be good candidates in the delivery of antifibrogenic miRNAs to HSCs, thus ameliorating hepatic fibrosis. Moreover, engineering native EVs may be a powerful way to improve the efficacy of native EVs. Also the EV-mediated delivery of IncRNAs, especially circRNAs, may represent a valid resource in the reversion of liver fibrosis and for this reason needs further investigation. Finally, determining which kind of cells in the liver are target for ncRNAs shuttled by EVs may help to better understand the patho-physiology of liver fibrosis and may open new therapeutic strategies.

\section{Abbreviations \\ ADSC: Adipose tissue-derived mesenchymal stromal cell; AlH: Autoimmune hepatitis; ALIX: Apoptosis-linked gene-2 interacting protein X; ALD: Alcoholic liver disease; a-SMA: Alpha smooth muscle actin; BDL: Bile duct ligation; BM- MSC: Bone marrow-derived mesenchymal stromal cell; $\mathrm{CCl}_{4}$ : Carbon tetrachloride; CCN2: Connective tissue growth factor; CCNG1: Cyclin G1; ceRNA: Competing endogenous RNA; circRNA: Circular RNA; CLI: Cholestatic liver injury; Col1a1: Alpha-1 type I collagen; CytP450s: Cytochrome P450 family; DILI: Drug-induced liver injury; ECM: Extracellular matrix; \\ EMT: Epithelial-to-mesenchymal transition; ESCRT: Endosomal sorting complex required for transport; EV: Extracellular vesicle; HBC: Hepatitis B virus; HCC: Hepatocellular cancer; HCV: Hepatitis C virus; HLSC: Human liver stem cell; HMGA2: High-mobility group AT-hook 2; HRS: Hepatocyte growth factor- regulated tyrosine kinase substrate; HSC: Hepatic stellate cell; IGF1R: Insulin- like growth factor receptor 1; IKBa: NF-KB inhibitor alpha; IL: Interleukin; iPSC: Human induced pluripotent stem cell; IncRNA: Long non-coding RNA; miRNA: MicroRNA; MSC: Mesenchymal stromal cell; MV: Microvesicle; MVB: Multivesicular body; NAFLD: Non-alcoholic fatty liver disease; NASH: Non-alcoholic steatohepatitis; ncRNA: Non-coding RNA; NF-kB: Nuclear factor kappa B; piRNA: Piwi-interacting RNA; P4HA1: Prolyl-4-hydroxylase a1; PDGF: Platelet-derived growth factor; PPARY: Peroxisome proliferator- activated receptor-gamma; PTEN: Phosphatase and tensin homolog; SHP: Small heterodimer partner; SK1: Sphingosine kinase 1; TGF- \\ $\beta$ : Transforming growth factor beta; TIMP2: Tissue inhibitor of metalloprotease-2; TNF-a: Tumor necrosis factor alpha; TSG101: Tumor susceptibility gene 101 protein; VPS4: Vacuolar protein sorting-associated protein 4}

Acknowledgements

The authors would like to thank Valeria Chiabotto for figure realization.

Authors' contributions

G.Ch. performed the research of the pertinent literature. G.Ch. and S.B. designed and drafted the manuscript. G.Ca. contributed to revising and editing the manuscript. All authors read and approved the final manuscript.

Funding

This work was supported by a grant from "Terapie avanzate per processi fibrotici cronici" (Progetto EV-ER, codice domanda 320-40, Regione Piemonte).

Availability of data and materials

Not applicable.

Ethics approval and consent to participate Not applicable.

Consent for publication

Not applicable.

\section{Competing interests}

G.Ca. is a component of Scientific Advisory Board of Unicyte AG. The authors declare no conflict of interest.

\section{Author details}

${ }^{1}$ Department of Medical Sciences, University of Torino, Corso Dogliotti 14 10126 Torino, Italy. ${ }^{2}$ Molecular Biotechnology Centre, University of Torino, Torino, Italy. 


\section{Received: 23 January 2020 Accepted: 29 April 2020}

\section{Published online: 18 May 2020}

\section{References}

1. Schuppan D, Kim YO. Evolving therapies for liver fibrosis. J Clin Invest. 2013; 123(5):1887-901.

2. Fagone P, Mangano K, Pesce A, Portale TR, Puleo S, Nicoletti F. Emerging therapeutic targets for the treatment of hepatic fibrosis. Drug Discovery Today. 2016;21(2):369-75.

3. Kisseleva T, Brenner DA. Hepatic stellate cells and the reversal of fibrosis. J Gastroenterol Hepatol. 2006;21(s3):S84-7.

4. Kisseleva T, Brenner DA. Role of hepatic stellate cells in fibrogenesis and the reversal of fibrosis. J Gastroenterol Hepatol. 2007;22(s1):S73-8.

5. Dooley S, ten Dijke P. TGF- $\beta$ in progression of liver disease. Cell Tissue Res. 2012;347(1):245-56.

6. Brenner DA. Transforming growth factor $B$ and hepatic fibrosis: cause or effect? Hepatology. 1991;14(4 Pt 1):740-2.

7. Tsukamoto H. Cytokine Regulation of Hepatic Stellate Cells in Liver Fibrosis. Alcohol Clin Exp Res. 1999;23(5):911-6.

8. Chen MH, Chen JC, Tsai CC, Wang WC, Chang DC, Tu DG, et al. The role of TGF- $\beta 1$ and cytokines in the modulation of liver fibrosis by Sho-saiko-to in rat's bile duct ligated model. J Ethnopharmacol. 2005;97(1):7-13.

9. Tong Z, Chen R, Alt DS, Kemper S, Perbal B, Brigstock DR. Susceptibility to liver fibrosis in mice expressing a connective tissue growth factor transgene in hepatocytes. Hepatology. 2009;50(3):939-47.

10. Brigstock DR. Connective tissue growth factor (CCN2, CTGF) and organ fibrosis: lessons from transgenic animals. J Cell Commun Signal. 2010:4(1):1-4

11. Gäbele E, Froh M, Arteel GE, Uesugi T, Hellerbrand C, Schölmerich J, et al. TNFa is required for cholestasis-induced liver fibrosis in the mouse. Biochem Biophys Res Commun. 2009;378(3):348-53.

12. Armendariz-Borunda J, Katayama K, Seyer JM. Transcriptional mechanisms of type I collagen gene expression are differentially regulated by interleukin-1 beta, tumor necrosis factor alpha, and transforming growth factor beta in Ito cells. J Biol Chem. 1992;267(20):14316-21.

13. Choi I, Kang HS, Yang Y, Pyun KH. IL-6 induces hepatic inflammation and collagen synthesis in vivo. Clin Exp Immunol. 1994:95(3):530-5.

14. Riaz F, Li D. Non-coding RNA Associated Competitive Endogenous RNA Regulatory Network: Novel Therapeutic Approach in Liver Fibrosis. Curr Gene Ther. 2019;19(5):305-17.

15. Kitano M, Bloomston PM. Hepatic Stellate Cells and microRNAs in Pathogenesis of Liver Fibrosis. J Clin Med. 2016;5(3):38.

16. Guo CJ, Xiao X, Sheng L, Chen L, Zhong W, Li H, Hua J, Ma X. RNA Sequencing and Bioinformatics Analysis Implicate the Regulatory Role of a Long Noncoding RNA-mRNA Network in Hepatic Stellate Cell Activation. Cell Physiol Biochem. 2017:42(5):2030-42.

17. Dong BS, Shi MJ, Su SB, Zhang H. Insight into long noncoding competing endogenous RNA networks in hepatic fibrosis: The potential implications for mechanism and therapy. Gene. 2019;687:255-60.

18. Roderburg C, Luedde T. Circulating microRNAs as markers of liver inflammation, fibrosis and cancer. J Hepatol. 2014;61(6):1434-7.

19. Hanson A, Wilhelmsen D, DiStefano JK. The Role of Long Non-Coding RNAs (IncRNAs) in the Development and Progression of Fibrosis Associated with Nonalcoholic Fatty Liver Disease (NAFLD). Noncoding RNA. 2018;21:4(3).

20. Lee RC, Feinbaum RL, Ambros $V$. The $C$. elegans heterochronic gene lin-4 encodes small RNAs with antisense complementarity to lin-14. Cell. 1993; 75(5):843-854.

21. Ambros $V$. The functions of animal microRNAs. Nature. 2004;431(7006): 350-5.

22. Bartel DP. MicroRNAs: Genomics, Biogenesis, Mechanism, and Function. Cell. 2004;116(2):281-97.

23. Yates LA, Norbury CJ, Gilbert RJC. The Long and Short of MicroRNA. Cell. 2013;153(3):516-9

24. Engels BM, Hutvagner G. Principles and effects of microRNA-mediated posttranscriptional gene regulation. Oncogene. 2006;25(46):6163-9.

25. Zimmerman AL, Wu S. MicroRNAs, cancer and cancer stem cells. Cancer Letters. 2011;300(1):10-9.

26. Arroyo JD, Chevillet JR, Kroh EM, Ruf IK, Pritchard CC, Gibson DF, et al. Argonaute2 complexes carry a population of circulating microRNAs independent of vesicles in human plasma. Proc Natl Acad Sci U S A. 2011; 108(12):5003-8.
27. Vickers KC, Palmisano BT, Shoucri BM, Shamburek RD, Remaley AT. MicroRNAs are transported in plasma and delivered to recipient cells by high-density lipoproteins. Nat Cell Biol. 2011;13(4):423-33.

28. Valadi H, Ekström K, Bossios A, Sjöstrand M, Lee JJ, Lötvall JO. Exosomemediated transfer of mRNAs and microRNAs is a novel mechanism of genetic exchange between cells. Nat Cell Biol. 2007;9(6):654-9.

29. Zernecke A, Bidzhekov K, Noels H, Shagdarsuren E, Gan L, Denecke B, et al. Delivery of microRNA-126 by apoptotic bodies induces CXCL12-dependent vascular protection. Sci Signal. 2009;2(100):ra81.

30. Salmanidis M, Pillman K, Goodall G, Bracken C. Direct transcriptional regulation by nuclear microRNAs. Int J Biochem Cell Biol. 2014;54:304-11.

31. Jovanovic M, Hengartner MO. miRNAs and apoptosis: RNAs to die for. Oncogene. 2006;25(46):6176-87.

32. Chen CZ, Li L, Lodish HF, Bartel DP. MicroRNAs modulate hematopoietic lineage differentiation. Science. 2004;303(5654):83-6.

33. Wilfred BR, Wang WX, Nelson PT. Energizing miRNA research: a review of the role of miRNAs in lipid metabolism, with a prediction that miR-103/107 regulates human metabolic pathways. Mol Genet Metab. 2007;91(3):209-17.

34. Szabo G, Bala S. MicroRNAs in liver disease. Nat Rev Gastroenterol Hepatol. 2013;10(9):542-52

35. DiStefano JK, Gerhard GS. Circulating microRNAs in nonalcoholic fatty liver disease. Exp Rev Gastroenterol Hepatol. 2016;10(2):161-3.

36. Bihrer $V$, Friedrich-Rust $M$, Kronenberger B, Forestier $N$, Haupenthal J, Shi $Y$, et al. Serum miR-122 as a biomarker of necroinflammation in patients with chronic hepatitis C virus infection. Am J Gastroenterol. 2011;106(9):1663-9.

37. Cermelli S, Ruggieri A, Marrero JA, loannou GN, Beretta L. Circulating microRNAs in patients with chronic hepatitis $C$ and non-alcoholic fatty liver disease. PLOS ONE. 2011;6(8):e23937.

38. Ji F, Yang B, Peng $X$, Ding $H$, You $H$, Tien $P$. Circulating microRNAs in hepatitis B virus-infected patients. J Viral Hepat. 2011;18(7):e242-51.

39. Waidmann O, Bihrer V, Pleli T, Farnik H, Berger A, Zeuzem S, et al. Serum microRNA-122 levels in different groups of patients with chronic hepatitis $B$ virus infection. J Viral Hepat. 2012;19(2):e58-65.

40. Zhang Y, Jia Y, Zheng R, Guo Y, Wang Y, Guo H, et al. Plasma microRNA-122 as a biomarker for viral-, alcohol-, and chemical-related hepatic diseases. Clin Chem. 2010:56(12):1830-8

41. Roderburg C, Benz F, Vargas Cardenas D, Koch A, Janssen J, Vucur M, et al. Elevated miR-122 serum levels are an independent marker of liver injury in inflammatory diseases. Liver Int. 2015;35(4):1172-84.

42. Starckx S, Batheja A, Verheyen GR, Jonghe SD, Steemans K, Dijck BV, et al. Evaluation of miR-122 and other biomarkers in distinct acute liver injury in rats. Toxicol Pathol. 2013;41(5):795-804.

43. Xu J, Wu C, Che X, Wang L, Yu D, Zhang T, et al. Circulating microRNAs, miR-21, miR-122, and miR-223, in patients with hepatocellular carcinoma or chronic hepatitis. Mol Carcinog. 2011:50(2):136-42.

44. Tryndyak VP, Latendresse JR, Montgomery B, Ross SA, Beland FA, Rusyn I, et al. Plasma microRNAs are sensitive indicators of inter-strain differences in the severity of liver injury induced in mice by a choline- and folate-deficient diet. Toxicol Appl Pharmacol. 2012;262(1):52-9.

45. Povero D, Eguchi A, Li H, Johnson CD, Papouchado BG, Wree A, et al. Circulating Extracellular Vesicles with Specific Proteome and Liver MicroRNAs Are Potential Biomarkers for Liver Injury in Experimental Fatty Liver Disease. PLOS ONE. 2014:9(12):e113651.

46. Bandyopadhyay S, Friedman RC, Marquez RT, Keck K, Kong B, Icardi MS, et al. Hepatitis $C$ virus infection and hepatic stellate cell activation downregulate miR-29: miR-29 overexpression reduces hepatitis $C$ viral abundance in culture. J Infect Dis. 2011;203(12):1753-62.

47. Wang J, Chu ESH, Chen HY, Man K, Go MYY, Huang XR, et al. microRNA-29b prevents liver fibrosis by attenuating hepatic stellate cell activation and inducing apoptosis through targeting PI3K/AKT pathway. Oncotarget. 2015; 6(9):7325-38.

48. Dai W, Zhao J, Tang N, Zeng X, Wu K, Ye C, et al. MicroRNA-155 attenuates activation of hepatic stellate cell by simultaneously preventing EMT process and ERK1 signalling pathway. Liver Int. 2015;35(4):1234-43.

49. Wei J, Feng $L, L i$ Z, Xu G, Fan X. MicroRNA-21 activates hepatic stellate cells via PTEN/Akt signaling. Biomed Pharmacother. 2013:67(5):387-92.

50. Zheng J, Wu C, Xu Z, Xia P, Dong P, Chen B, et al. Hepatic stellate cell is activated by microRNA-181b via PTEN/Akt pathway. Mol Cell Biochem. 2015; 398(1):1-9.

51. Li ZJ, Ou-Yang PH, Han XP. Profibrotic effect of miR-33a with Akt activation in hepatic stellate cells. Cellular Signalling. 2014;26(1):141-8. 
52. Li X, Chen Y, Wu S, He J, Lou L, Ye W, et al. microRNA-34a and microRNA-34c promote the activation of human hepatic stellate cells by targeting peroxisome proliferator-activated receptor $\gamma$. Mol Med Rep. 2015;11(2):1017-24.

53. Feng $X$, Tan W, Cheng S, Wang $H_{1}$ Ye $S$, Yu C, et al. Upregulation of microRNA-126 in hepatic stellate cells may affect pathogenesis of liver fibrosis through the NF-KB pathway. DNA Cell Biol. 2015;34(7):470-80.

54. Ogawa T, Enomoto M, Fujii H, Sekiya Y, Yoshizato K, Ikeda K, et al. MicroRNA-221/222 upregulation indicates the activation of stellate cells and the progression of liver fibrosis. Gut. 2012;61(11):1600-9.

55. Okazaki Y, Furuno M, Kasukawa T, Adachi J, Bono H, Kondo S, et al. Analysis of the mouse transcriptome based on functional annotation of 60,770 fulllength cDNAs. Nature. 2002;420(6915):563-73.

56. Guttman M, Amit I, Garber M, French C, Lin MF, Feldser D, et al. Chromatin signature reveals over a thousand highly conserved large non-coding RNAs in mammals. Nature. 2009:458(7235):223-7.

57. Mercer TR, Dinger ME, Mattick JS. Long non-coding RNAs: insights into functions. Nat Rev Genet. 2009;10(3):155-9.

58. Ghidini M, Braconi C. Non-Coding RNAs in Primary Liver Cancer. Front Med (Lausanne). 2015;2:36.

59. Tang JY, Lee JC, Chang YT, Hou MF, Huang HW, Liaw CC, et al. Long noncoding RNAs-related diseases, cancers, and drugs. ScientificWorldJ. 2013; 2013:943539.

60. Zhang K, Shi ZM, Chang YN, Hu ZM, Qi HX, Hong W. The ways of action of long non-coding RNAs in cytoplasm and nucleus. Gene. 2014;547(1):1-9.

61. Wang KC, Chang HY. Molecular Mechanisms of Long Noncoding RNAs. Molecular Cell. 2011;43(6):904-14.

62. Lai F, Orom UA, Cesaroni M, Beringer M, Taatjes DJ, Blobel GA, et al. Activating RNAs associate with Mediator to enhance chromatin architecture and transcription. Nature. 2013;494(7438):497-501.

63. Gonzalez I, Munita R, Agirre E, Dittmer TA, Gysling K, Misteli T, et al. A IncRNA regulates alternative splicing via establishment of a splicing-specific chromatin signature. Nat Struct Mol Biol. 2015;22(5):370-6.

64. Scarola M, Comisso E, Pascolo R, Chiaradia R, Marion RM, Schneider C, et al. Epigenetic silencing of Oct4 by a complex containing SUV39H1 and Oct4 pseudogene IncRNA. Nat Commun. 2015;6:7631.

65. Liu B, Ye B, Yang L, Zhu X, Huang G, Zhu P, et al. Long noncoding RNA IncKdm2b is required for ILC3 maintenance by initiation of Zfp292 expression. Nat Immunol. 2017;18(5):499-508.

66. Wang XQD, Dostie J. Reciprocal regulation of chromatin state and architecture by HOTAIRM1 contributes to temporal collinear HOXA gene activation. Nucleic Acids Res. 2017;45(3):1091-104.

67. Giroud M, Scheideler M. Long Non-Coding RNAs in Metabolic Organs and Energy Homeostasis. Int J Mol Sci. 2017;18(12):E2578.

68. Gupta RA, Shah N, Wang KC, Kim J, Horlings HM, Wong DJ, et al. Long noncoding RNA HOTAIR reprograms chromatin state to promote cancer metastasis. Nature. 2010;464(7291):1071-6.

69. Huarte M, Rinn JL. Large non-coding RNAs: missing links in cancer? Hum Mol Genet. 2010;19(R2):R152-61.

70. Li L, Feng T, Lian Y, Zhang G, Garen A, Song X. Role of human noncoding RNAs in the control of tumorigenesis. Proc Natl Acad Sci USA. 2009;106(31): 12956-61.

71. Sheik Mohamed J, Gaughwin PM, Lim B, Robson P, Lipovich L. Conserved long noncoding RNAs transcriptionally regulated by Oct4 and Nanog modulate pluripotency in mouse embryonic stem cells. RNA. 2010;16(2): 324-37.

72. Yu F, Chen B, Dong P, Zheng J. HOTAIR Epigenetically Modulates PTEN Expression via MicroRNA-29b: A Novel Mechanism in Regulation of Liver Fibrosis. Mol Ther. 2017;25(1):205-17.

73. Bian EB, Wang YY, Yang Y, Wu BM, Xu T, Meng XM, et al. Hotair facilitates hepatic stellate cells activation and fibrogenesis in the liver. Biochimica et Biophysica Acta (BBA) - Molecular Basis of Disease. 2017;1863(3):674-86.

74. He Y, Wu Y, Huang C, Meng XM, Ma T, Wu BM, et al. Inhibitory effects of long noncoding RNA MEG3 on hepatic stellate cells activation and liver fibrogenesis. Biochimica et Biophysica Acta (BBA) - Molecular Basis of Disease. 2014;1842(11):2204-15

75. Zhang QQ, Xu MY, Qu Y, Hu JJ, Li ZH, Zhang QD, et al. TET3 mediates the activation of human hepatic stellate cells via modulating the expression of long non-coding RNA HIF1A-AS1. Int J Clin Exp Pathol. 2014;7(11):7744-51.

76. Zheng J, Yu F, Dong P, Wu L, Zhang Y, Hu Y, et al. Long non-coding RNA PVT1 activates hepatic stellate cells through competitively binding microRNA-152. Oncotarget. 2016;7(39):62886-97.
77. Yu F, Zheng J, Mao Y, Dong P, Li G, Lu Z, et al. Long non-coding RNA APTR promotes the activation of hepatic stellate cells and the progression of liver fibrosis. Biochem Biophys Res Commun. 2015;463(4):679-85.

78. Zheng J, Dong P, Mao Y, Chen S, Wu X, Li G, et al. lincRNA-p21 inhibits hepatic stellate cell activation and liver fibrogenesis via p21. FEBS J. 2015; 282(24):4810-21.

79. Yu F, Guo Y, Chen B, Shi L, Dong P, Zhou M, et al. LincRNA-p21 Inhibits the Wnt/ß-Catenin Pathway in Activated Hepatic Stellate Cells via Sponging MicroRNA-17-5p. Cell Physiol Biochem. 2017;41(5):1970-80.

80. Li X, Yang L, Chen LL. The Biogenesis, Functions, and Challenges of Circular RNAs. Mol Cell. 2018:71(3):428-42.

81. Yu CY, Kuo HC. The emerging roles and functions of circular RNAs and their generation. J Biomed Sci. 2019;26(1):29.

82. Barrett SP, Salzman J. Circular RNAs: analysis, expression and potential functions. Development. 2016:143(11):1838-47.

83. Kulcheski FR, Christoff AP, Margis R. Circular RNAs are miRNA sponges and can be used as a new class of biomarker. J Biotechnol. 2016;238:42-51.

84. Chien Y, Tsai PH, Lai YH, Lu KH, Liu CY, Lin HF, et al. CircularRNA as novel biomarkers in liver diseases. J Chin Med Assoc. 2020;83(1):15-7.

85. Chen $Y$, Yuan B, Wu Z, Dong Y, Zhang L, Zeng Z. Microarray profiling of circular RNAs and the potential regulatory role of hsa circ 0071410 in the activated human hepatic stellate cell induced by irradiation. Gene. 2017;629:35-42.

86. Zhou Y, Lv X, Qu H, Zhao K, Fu L, Zhu L, et al. Differential expression of circular RNAs in hepatic tissue in a model of liver fibrosis and functional analysis of their target genes. Hepatol Res. 2019;49(3):324-34.

87. Wang W, Dong R, Guo Y, He J, Shao C, Yi P, et al. CircMTO1 inhibits liver fibrosis via regulation of miR-17-5p and Smad7. J Cell Mol Med. 2019; 23(8):5486-96

88. Liu W, Feng R, Li X, Li D, Zhai W. TGF- $\beta$ - and lipopolysaccharide-induced upregulation of circular RNA PWWP2A promotes hepatic fibrosis via sponging miR-203 and miR-223. Aging (Albany NY). 2019;11(21):9569-80.

89. Li Y, Gao X, Wang Z, Liu W, Xu F, Hu Y, et al. Circular RNA 4099 aggravates hydrogen peroxide-induced injury by down-regulating microRNA-706 in L02 cells. Life Sci. 2020;241:116826.

90. Cocucci E, Meldolesi J. Ectosomes and exosomes: shedding the confusion between extracellular vesicles. Trends Cell Biol. 2015;25(6):364-72.

91. Yáñez-Mó M, Siljander PRM, Andreu Z, Zavec AB, Borràs FE, Buzas El, et al. Biological properties of extracellular vesicles and their physiological functions. J Extracell Vesicles. 2015:4:27066.

92. Kowal J, Tkach M, Théry C. Biogenesis and secretion of exosomes. Curr Opin Cell Biol. 2014;29:116-25.

93. Hanson PI, Cashikar A. Multivesicular body morphogenesis. Annu Rev Cell Dev Biol. 2012;28:337-62.

94. Hurley JH, Odorizzi G. Get on the exosome bus with ALIX. Nat Cell Biol. 2012;14(7):654-5.

95. Tamai K, Tanaka N, Nakano T, Kakazu E, Kondo Y, Inoue J, et al. Exosome secretion of dendritic cells is regulated by Hrs, an ESCRT-0 protein. Biochem Biophys Res Commun. 2010:399(3):384-90.

96. Razi M, Futter CE. Distinct roles for Tsg101 and Hrs in multivesicular body formation and inward vesiculation. Mol Biol Cell. 2006;17(8):3469-83.

97. Baietti MF, Zhang Z, Mortier E, Melchior A, Degeest G, Geeraerts A, et al. Syndecan-syntenin-ALIX regulates the biogenesis of exosomes. Nat Cell Biol. 2012;14(7):677-85.

98. Babst M, Davies BA, Katzmann DJ. Regulation of Vps4 during MVB sorting and cytokinesis. Traffic. 2011;12(10):1298-305.

99. Stuffers S, Sem Wegner C, Stenmark H, Brech A. Multivesicular endosome biogenesis in the absence of ESCRTs. Traffic. 2009;10(7):925-37.

100. Andreu Z, Yáñez-Mó M. Tetraspanins in extracellular vesicle formation and function. Front Immunol. 2014:5:442.

101. van Niel G, Charrin S, Simoes S, Romao M, Rochin L, Saftig P, et al. The tetraspanin CD63 regulates ESCRT-independent and -dependent endosomal sorting during melanogenesis. Dev Cell. 2011;21(4):708-21.

102. Chairoungdua A, Smith DL, Pochard P, Hull M, Caplan MJ. Exosome release of $\beta$-catenin: a novel mechanism that antagonizes Wnt signaling. J Cell Biol. 2010;190(6):1079-91.

103. Nazarenko I, Rana S, Baumann A, McAlear J, Hellwig A, Trendelenburg M, et al. Cell surface tetraspanin Tspan8 contributes to molecular pathways of exosome-induced endothelial cell activation. Cancer Res. 2010;70(4):1668-78.

104. Perez-Hernandez D, Gutiérrez-Vázquez C, Jorge I, López-Martín S, Ursa A, Sánchez-Madrid F, et al. The intracellular interactome of tetraspanin- 
enriched microdomains reveals their function as sorting machineries toward exosomes. J Biol Chem. 2013;288(17):11649-61.

105. Hyenne V, Apaydin A, Rodriguez D, Spiegelhalter C, Hoff-Yoessle S, Diem M, et al. RAL-1 controls multivesicular body biogenesis and exosome secretion. J Cell Biol. 2015;211(1):27-37.

106. Stenmark H. Rab GTPases as coordinators of vesicle traffic. Nat Rev Mol Cell Biol. 2009;10(8):513-25.

107. Ostrowski M, Carmo NB, Krumeich S, Fanget I, Raposo G, Savina A, et al. Rab27a and Rab27b control different steps of the exosome secretion pathway. Nat Cell Biol. 2010;12(1):19-30 sup pp 1-13.

108. Bobrie A, Krumeich S, Reyal F, Recchi C, Moita LF, Seabra MC, et al. Rab27a supports exosome-dependent and -independent mechanisms that modify the tumor microenvironment and can promote tumor progression. Cancer Res. 2012;72(19):4920-30.

109. Hsu C, Morohashi Y, Yoshimura S-I, Manrique-Hoyos N, Jung S, Lauterbach MA, et al. Regulation of exosome secretion by Rab35 and its GTPaseactivating proteins TBC1D10A-C. J Cell Biol. 2010;189(2):223-32.

110. Trajkovic K, Hsu C, Chiantia S, Rajendran L, Wenzel D, Wieland F, et al. Ceramide triggers budding of exosome vesicles into multivesicular endosomes. Science. 2008;319(5867):1244-7.

111. van Niel G, D'Angelo G, Raposo G. Shedding light on the cell biology of extracellular vesicles. Nat Rev Mol Cell Biol. 2018;19:213-228.Abels ER, Breakefield XO. Introduction to Extracellular Vesicles: Biogenesis, RNA Cargo Selection, Content, Release, and Uptake. Cell Mol Neurobiol. 2016;36(3):301-12.

112. Tricarico C, Clancy J, D'Souza-Schorey C. Biology and biogenesis of shed microvesicles. Small GTPases. 2017;8(4):220-32.

113. Nabhan JF, Hu R, Oh RS, Cohen SN, Lu Q. Formation and release of arrestin domain-containing protein 1-mediated microvesicles (ARMMs) at plasma membrane by recruitment of TSG101 protein. Proc Natl Acad Sci USA. 2012 109(11):4146-51

114. Muralidharan-Chari V, Clancy J, Plou C, Romao M, Chavrier P, Raposo G, et al. ARF6-regulated shedding of tumor cell-derived plasma membrane microvesicles. Curr Biol. 2009;19(22):1875-85.

115. Pellon-Cardenas O, Clancy J, Uwimpuhwe H, D'Souza-Schorey C. ARF6regulated endocytosis of growth factor receptors links cadherin-based adhesion to canonical Wnt signaling in epithelia. Mol Cell Biol. 2013;33(15): 2963-75.

116. Hristov M, Erl W, Linder S, Weber PC. Apoptotic bodies from endothelial cells enhance the number and initiate the differentiation of human endothelial progenitor cells in vitro. Blood. 2004;104(9):2761-6.

117. Lee TH, D'Asti E, Magnus N, Al-Nedawi K, Meehan B, Rak J. Microvesicles as mediators of intercellular communication in cancer--the emerging science of cellular «debris». Semin Immunopathol. 2011;33(5):455-67.

118. Li CCY, Eaton SA, Young PE, Lee M, Shuttleworth R, Humphreys DT, et al. Glioma microvesicles carry selectively packaged coding and non-coding RNAs which alter gene expression in recipient cells. RNA Biol. 2013;10(8): 1333-44.

119. Villarroya-Beltri C, Baixauli F, Gutiérrez-Vázquez C, Sánchez-Madrid F, Mittelbrunn M. Sorting it out: regulation of exosome loading. Semin Cancer Biol. 2014;28:3-13.

120. Quesenberry PJ, Aliotta J, Deregibus MC, Camussi G. Role of extracellular RNA-carrying vesicles in cell differentiation and reprogramming. Stem Cell Res Ther. 2015;6:153.

121. Deregibus MC, Cantaluppi V, Calogero R, Lo lacono M, Tetta C, Biancone L, et al. Endothelial progenitor cell derived microvesicles activate an angiogenic program in endothelial cells by a horizontal transfer of mRNA. Blood. 2007;110(7):2440-8.

122. Skog J, Würdinger T, van Rijn S, Meijer DH, Gainche L, Sena-Esteves M, et al. Glioblastoma microvesicles transport RNA and proteins that promote tumour growth and provide diagnostic biomarkers. Nat Cell Biol. 2008; 10(12):1470-6.

123. Ekström $K$, Valadi $H$, Sjöstrand M, Malmhäll C, Bossios A, Eldh M, et al. Characterization of mRNA and microRNA in human mast cell-derived exosomes and their transfer to other mast cells and blood CD34 progenitor cells. J Extracell Vesicles. 2012;1:18389.

124. Nolte-'t Hoen ENM, Buermans HPJ, Waasdorp M, Stoorvogel W, Wauben MHM. 't Hoen PAC. Deep sequencing of RNA from immune cell-derived vesicles uncovers the selective incorporation of small non-coding RNA biotypes with potential regulatory functions. Nucleic Acids Res. 2012;40(18): 9272-85.
125. Boon RA, Vickers KC. Intercellular transport of microRNAs. Arterioscler Thromb Vasc Biol. 2013;33(2):186-92.

126. Cheng L, Sun X, Scicluna BJ, Coleman BM, Hill AF. Characterization and deep sequencing analysis of exosomal and non-exosomal miRNA in human urine. Kidney Int. 2014;86(2):433-44.

127. Crescitelli R, Lässer C, Szabó TG, Kittel A, Eldh M, Dianzani I, et al. Distinct RNA profiles in subpopulations of extracellular vesicles: apoptotic bodies, microvesicles and exosomes. J Extracell Vesicles. 2013;2:20677.

128. Hill AF, Pegtel DM, Lambertz U, Leonardi T, O'Driscoll L, Pluchino S, et al. ISEV position paper: extracellular vesicle RNA analysis and bioinformatics. $J$ Extracell Vesicles, 2013:2:22859.

129. Huang $X$, Yuan T, Tschannen M, Sun Z, Jacob H, Du M, et al. Characterization of human plasma-derived exosomal RNAs by deep sequencing. BMC Genomics. 2013;14:319.

130. Ogawa Y, Taketomi Y, Murakami M, Tsujimoto M, Yanoshita R. Small RNA transcriptomes of two types of exosomes in human whole saliva determined by next generation sequencing. Biol Pharm Bull. 2013;36(1):66-75.

131. Wei Z, Batagov AO, Schinelli S, Wang J, Wang Y, El Fatimy R, et al. Coding and noncoding landscape of extracellular RNA released by human glioma stem cells. Nat Commun. 2017:8(1):1145.

132. Li Y, Zheng Q, Bao C, Li S, Guo W, Zhao J, et al. Circular RNA is enriched and stable in exosomes: a promising biomarker for cancer diagnosis. Cell Res. 2015;25(8):981-4.

133. Batagov AO, Kurochkin IV. Exosomes secreted by human cells transport largely mRNA fragments that are enriched in the 3'-untranslated regions. Biol Direct. 2013;8:12.

134. Chen L, Brenner DA, Kisseleva T. Combatting Fibrosis: Exosome-Based Therapies in the Regression of Liver Fibrosis. Hepatol Commun. 2018;3(2): 180-92.

135. Feldstein $A E$, Canbay A, Angulo $P$, Taniai M, Burgart $L$, Lindor $K D$, et al. Hepatocyte apoptosis and fas expression are prominent features of human nonalcoholic steatohepatitis. Gastroenterology. 2003;125(2):437-43.

136. Ribeiro PS, Cortez-Pinto H, Solá S, Castro RE, Ramalho RM, Baptista A, et al. Hepatocyte apoptosis, expression of death receptors, and activation of NFkappaB in the liver of nonalcoholic and alcoholic steatohepatitis patients. Am J Gastroenterol. 2004:99(9):1708-17.

137. Conde-Vancells J, Rodriguez-Suarez E, Embade N, Gil D, Matthiesen R, Valle $M$, et al. Characterization and comprehensive proteome profiling of exosomes secreted by hepatocytes. J Proteome Res. 2008;7(12):5157-66.

138. Cho EY, Yun CH, Chae HZ, Chae HJ, Ahn T. Anionic phospholipid-induced regulation of reactive oxygen species production by human cytochrome P450 2E1. FEBS Lett. 2008;582(12):1771-6.

139. Seo W, Eun HS, Kim SY, Yi HS, Lee YS, Park SH, et al. Exosome-mediated activation of toll-like receptor 3 in stellate cells stimulates interleukin-17 production by $\gamma \delta$ T cells in liver fibrosis. Hepatology. 2016;64(2):616-31.

140. Ma HY, Xu J, Liu X, Zhu Y, Gao B, Karin M, et al. The role of IL-17 signaling in regulation of the liver-brain axis and intestinal permeability in Alcoholic Liver Disease. Curr Pathobiol Rep. 2016;4(1):27-35.

141. Leask A, Abraham DJ. All in the CCN family: essential matricellular signaling modulators emerge from the bunker. J Cell Sci. 2006;119(Pt 23):4803-10.

142. Paradis V, Dargere D, Vidaud M, De Gouville AC, Huet S, Martinez V, et al. Expression of connective tissue growth factor in experimental rat and human liver fibrosis. Hepatology. 1999;30(4):968-76.

143. Williams EJ, Gaça MD, Brigstock DR, Arthur MJ, Benyon RC. Increased expression of connective tissue growth factor in fibrotic human liver and in activated hepatic stellate cells. J Hepatol. 2000;32(5):754-61.

144. Borges FT, Melo SA, Özdemir BC, Kato N, Revuelta I, Miller CA, et al. TGF-B1containing exosomes from injured epithelial cells activate fibroblasts to initiate tissue regenerative responses and fibrosis. J Am Soc Nephrol. 2013; 24(3):385-92.

145. Charrier A, Chen R, Chen L, Kemper S, Hattori T, Takigawa M, et al. Exosomes mediate intercellular transfer of pro-fibrogenic connective tissue growth factor (CCN2) between hepatic stellate cells, the principal fibrotic cells in the liver. Surgery. 2014;156(3):548-55.

146. Wang R, Ding Q, Yaqoob U, de Assuncao TM, Verma VK, Hirsova P, et al. Exosome Adherence and Internalization by Hepatic Stellate Cells Triggers Sphingosine 1-Phosphate-dependent Migration. J Biol Chem. 2015;290(52): 30684-96.

147. Thabut D, Shah V. Intrahepatic angiogenesis and sinusoidal remodeling in chronic liver disease: new targets for the treatment of portal hypertension? J Hepatol. 2010;53(5):976-80. 
148. Povero D, Eguchi A, Niesman IR, Andronikou N, de Mollerat du Jeu X, Mulya $A$, et al. Lipid-induced toxicity stimulates hepatocytes to release angiogenic microparticles that require Vanin-1 for uptake by endothelial cells. Sci Signal. 2013;6(296):ra88.

149. Witek RP, Yang L, Liu R, Jung Y, Omenetti A, Syn WK, et al. Liver cell-derived microparticles activate hedgehog signaling and alter gene expression in hepatic endothelial cells. Gastroenterology. 2009;136(1):320-30 e2.

150. Valla DC. Thrombosis and anticoagulation in liver disease. Hepatology. 2008; 47(4):1384-93.

151. Anstee QM, Dhar A, Thursz MR. The role of hypercoagulability in liver fibrogenesis. Clin Res Hepatol Gastroenterol. 2011;35(8-9):526-33.

152. Dhar A, Mullish BH, Thursz MR. Anticoagulation in chronic liver disease. J Hepatol. 2017;66(6):1313-26.

153. Nieuwland R, Berckmans RJ, McGregor S, Böing AN, Romijn FP, Westendorp $\mathrm{RG}$, et al. Cellular origin and procoagulant properties of microparticles in meningococcal sepsis. Blood. 2000;95(3):930-5

154. Owens AP, Mackman N. Microparticles in hemostasis and thrombosis. Circ Res. 2011;108(10):1284-97.

155. He Y, Huang C, Zhang S, Sun X, Long X, Li J. The potential of microRNAs in liver fibrosis. Cell Signal. 2012;24(12):2268-72.

156. Noetel A, Kwiecinski M, Elfimova N, Huang J, Odenthal M. microRNA are Central Players in Anti- and Profibrotic Gene Regulation during Liver Fibrosis. Front Physiol. 2012;3:49.

157. Xiao Y, Liu R, Li X, Gurley EC, Hylemon PB, Lu Y, et al. Long Noncoding RNA H19 Contributes to Cholangiocyte Proliferation and Cholestatic Liver Fibrosis in Biliary Atresia. Hepatology. 2019;70(5):1658-73.

158. Liu R, Li X, Zhu W, Wang Y, Zhao D, Wang X, et al. Cholangiocyte-Derived Exosomal Long Noncoding RNA H19 Promotes Hepatic Stellate Cell Activation and Cholestatic Liver Fibrosis. Hepatology. 2019;70(4):1317-35

159. Li X, Liu R, Huang Z, Gurley EC, Wang X, Wang J, et al. Cholangiocytederived exosomal long noncoding RNA H19 promotes cholestatic liver injury in mouse and humans. Hepatology. 2018;68(2):599-615.

160. Dai X, Chen C, Xue J, Xiao T, Mostofa G, Wang D, et al. Exosomal MALAT1 derived from hepatic cells is involved in the activation of hepatic stellate cells via miRNA-26b in fibrosis induced by arsenite. Toxicol Lett. 2019;316: 73-84.

161. Povero D, Panera N, Eguchi A, Johnson CD, Papouchado BG, de Araujo HL, et al. Lipid-Induced Hepatocyte-Derived Extracellular Vesicles Regulate Hepatic Stellate Cells via MicroRNA Targeting Peroxisome ProliferatorActivated Receptor-ү. Cell Mol Gastroenterol Hepatol. 2015;1(6):646-63 e4.

162. Brandon-Warner E, Feilen NA, Culberson CR, Field CO. deLemos AS, Russo MW, et al. Processing of miR17-92 Cluster in Hepatic Stellate Cells Promotes Hepatic Fibrogenesis During Alcohol-Induced Injury. Alcohol Clin Exp Res. 2016:40(7):1430-42.

163. Devhare PB, Sasaki R, Shrivastava S, Di Bisceglie AM, Ray R, Ray RB. ExosomeMediated Intercellular Communication between Hepatitis C Virus-Infected Hepatocytes and Hepatic Stellate Cells. J Virol. 2017;91(6):e02225-16.

164. Matsuura K, Giorgi VD, Schechterly C, Wang RY, Farci P, Tanaka Y, et al. Circulating let-7 levels in plasma and extracellular vesicles correlate with hepatic fibrosis progression in chronic hepatitis C. Hepatology. 2016;64(3):732-45.

165. Lee YS, Kim SY, Ko E, Lee JH, Yi HS, Yoo YJ, et al. Exosomes derived from palmitic acid-treated hepatocytes induce fibrotic activation of hepatic stellate cells. Sci Rep. 2017;7(1):1-10.

166. Bukong TN, Momen-Heravi F, Kodys K, Bala S, Szabo G. Exosomes from Hepatitis C Infected Patients Transmit HCV Infection and Contain Replication Competent Viral RNA in Complex with Ago2-miR122-HSP90. PLOS Pathogens. 2014;10(10):e1004424.

167. Lou G, Yang Y, Liu F, Ye B, Chen Z, Zheng M, et al. MiR-122 modification enhances the therapeutic efficacy of adipose tissue-derived mesenchymal stem cells against liver fibrosis. J Cell Mol Med. 2017;21(11):2963-73.

168. Csak T, Bala S, Lippai D, Satishchandran A, Catalano D, Kodys K, et al. microRNA-122 regulates hypoxia-inducible factor-1 and vimentin in hepatocytes and correlates with fibrosis in diet-induced steatohepatitis. Liver International. 2015;35(2):532-41.

169. Bala S, Petrasek J, Mundkur S, Catalano D, Levin I, Ward J, et al. Circulating microRNAs in exosomes indicate hepatocyte injury and inflammation in alcoholic, drug-induced, and inflammatory liver diseases. Hepatology. 2012; 56(5):1946-57.

170. Momen-Heravi F, Bala S, Kodys K, Szabo G. Exosomes derived from alcoholtreated hepatocytes horizontally transfer liver specific miRNA-122 and sensitize monocytes to LPS. Sci Rep. 2015;5:9991.
171. Qu Y, Zhang Q, Cai X, Li F, Ma Z, Xu M, et al. Exosomes derived from miR-181$5 p$-modified adipose-derived mesenchymal stem cells prevent liver fibrosis via autophagy activation. J Cell Mol Med. 2017;21(10):2491-502.

172. Kim JH, Lee CH, Lee SW. Exosomal Transmission of MicroRNA from HCV Replicating Cells Stimulates Transdifferentiation in Hepatic Stellate Cells. Mol Ther Nucleic Acids. 2019;14:483-97.

173. Chen L, Chen R, Velazquez VM, Brigstock DR. Fibrogenic Signaling Is Suppressed in Hepatic Stellate Cells through Targeting of Connective Tissue Growth Factor (CCN2) by Cellular or Exosomal MicroRNA-199a-5p. Am J Pathol. 2016;186(11):2921-33.

174. Chen L, Charrier A, Zhou Y, Chen R, Yu B, Agarwal K, et al. Epigenetic regulation of connective tissue growth factor by microRNA-214 delivery in exosomes from mouse or human hepatic stellate cells. Hepatology. 2014; 59(3):1118-29.

175. Chen L, Chen R, Kemper S, Charrier A, Brigstock DR. Suppression of fibrogenic signaling in hepatic stellate cells by Twist1-dependent microRNA214 expression: Role of exosomes in horizontal transfer of Twist1. Am J Physiol Gastrointestinal Liver Physiol. 2015;309(6):G491-9.

176. Povero D, Pinatel EM, Leszczynska A, Goyal NP, Nishio T, Kim J, et al. Human induced pluripotent stem cell-derived extracellular vesicles reduce hepatic stellate cell activation and liver fibrosis. JCI Insight. 2019:5:125652.

177. Chen L, Lu FB, Chen DZ, Wu JL, Hu ED, Xu LM, et al. BMSCs-derived miR223-containing exosomes contribute to liver protection in experimental autoimmune hepatitis. Mol Immunol. 2018;93:38-46.

178. Chen J, Yu Y, Li S, Liu Y, Zhou S, Cao S, et al. MicroRNA-30a ameliorates hepatic fibrosis by inhibiting Beclin1-mediated autophagy. J Cell Mol Med. 2017;21(12):3679-92.

179. Chen L, Chen R, Kemper S, Cong M, You H, Brigstock DR. Therapeutic effects of serum extracellular vesicles in liver fibrosis. J Extracell Vesicles. 2018:7(1):1461505

180. Hirsova P, Ibrahim SH, Krishnan A, Verma VK, Bronk SF, Werneburg NW, et al. Lipid-Induced Signaling Causes Release of Inflammatory Extracellular Vesicles From Hepatocytes. Gastroenterology. 2016;150(4):956-67.

181. Mendell JT. miRiad roles for the miR-17-92 cluster in development and disease. Cell. 2008;133(2):217-22.

182. Rottiers $V$, Näär AM. MicroRNAs in metabolism and metabolic disorders. Nat Rev Mol Cell Biol. 2012;13(4):239-50.

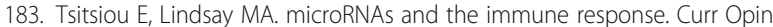
Pharmacol. 2009;9(4):514-20

184. Liu C, Tang DG. MicroRNA regulation of cancer stem cells. Cancer Res. 2011; 71(18):5950-4.

185. Zhu H, Han C, Wu T. MiR-17-92 cluster promotes hepatocarcinogenesis. Carcinogenesis. 2015;36(10):1213-22.

186. Nakao K, Miyaaki H, Ichikawa T. Antitumor function of microRNA-122 against hepatocellular carcinoma. J Gastroenterol. 2014;49(4):589-93.

187. Leti F, Legendre C, Still CD, Chu X, Petrick A, Gerhard GS, et al. Altered expression of MALAT1 IncRNA in nonalcoholic steatohepatitis fibrosis regulates CXCL5 in hepatic stellate cells. Transl Res. 2017;190: 25-39 e21.

188. Yu F, Lu Z, Cai J, Huang K, Chen B, Li G, et al. MALAT1 functions as a competing endogenous RNA to mediate Rac1 expression by sequestering miR-101b in liver fibrosis. Cell Cycle. 2015;14(24):3885-96.

189. Li X, Liu R, Yang J, Sun L, Zhang L, Jiang Z, et al. The role of long noncoding RNA H19 in gender disparity of cholestatic liver injury in multidrug resistance 2 gene knockout mice. Hepatology. 2017:66(3): 869-84.

190. Zhang Y, Liu C, Barbier O, Smalling R, Tsuchiya $H$, Lee $S$, et al. Bcl2 is a critical regulator of bile acid homeostasis by dictating Shp and IncRNA H19 function. Sci Rep. 2016;6:20559.

191. Yuan CT, Li XX, Cheng QJ, Wang YH, Wang JH, Liu CL. MiR-30a regulates the atrial fibrillation-induced myocardial fibrosis by targeting snail 1. Int J Clin Exp Pathol. 2015:8(12):15527-36.

192. Zhou Q, Yang M, Lan H, Yu X. miR-30a negatively regulates TGF- $\beta 1$-induced epithelial-mesenchymal transition and peritoneal fibrosis by targeting Snai1. Am J Pathol. 2013;183(3):808-19.

193. Zheng J, Wang W, Yu F, Dong P, Chen B, Zhou MT. MicroRNA-30a Suppresses the Activation of Hepatic Stellate Cells by Inhibiting Epithelialto-Mesenchymal Transition. Cell Physiol Biochem. 2018;46(1):82-92

194. Bruno S, Kholia S, Deregibus MC, Camussi G. The role of extracellular vesicles as paracrine effectors in stem cell-based therapies. Adv Exp Med Biol. 2019;1201:175-93. 
195. Lou G, Chen Z, Zheng M, Liu Y. Mesenchymal stem cell-derived exosomes as a new therapeutic strategy for liver diseases. Exp Mol Med. 2017;49(6):e346.

196. Fiore EJ, Domínquez LM, Bayo J, García MG, Mazzolini GD. Taking advantage of the potential of mesenchymal stromal cells in liver regeneration: Cells and extracellular vesicles as therapeutic strategies. World I Gastroenterol. 2018;24(23):2427-40.

197. Bruno S, Pasquino C, Herrera Sanchez MB, Tapparo M, Figliolini F, Grange C, et al. HLSC-Derived Extracellular Vesicles Attenuate Liver Fibrosis and Inflammation in a Murine Model of Non-alcoholic Steatohepatitis. Mol Ther. 2020;28(2):479-89.

198. Kholia S, Herrera Sanchez MB, Cedrino M, Papadimitriou E, Tapparo M, Deregibus MC, Brizzi MF, Tetta C, Camussi G. Human Liver Stem CellDerived Extracellular Vesicles Prevent Aristolochic Acid-Induced Kidney Fibrosis. Front Immunol. 2018:9:1639.

199. Grange C, Tritta S, Tapparo M, Cedrino M, Tetta C, Camussi G, Brizzi MF. Stem cell-derived extracellular vesicles inhibit and revert fibrosis progression in a mouse model of diabetic nephropathy. Sci Rep. 2019;9(1):4468.

200. Mohankumar S, Patel T. Extracellular vesicle long noncoding RNA as potential biomarkers of liver cancer. Brief Funct Genomics. 2016;15(3): 249-56.

201. Maji S, Matsuda A, Yan IK, Parasramka M, Patel T. Extracellular vesicles in liver diseases. Am J Physiol Gastrointestinal Liver Physiol. 2016;312(3):G194-200.

202. Li F, Ma N, Zhao R, Wu G, Zhang Y, Qiao Y, et al. Overexpression of miR483-5p/3p cooperate to inhibit mouse liver fibrosis by suppressing the TGFB stimulated HSCs in transgenic mice. J Cell Mol Med. 2014;18(6):966-74.

203. Leask A, Chen S, Pala D, Brigstock DR. Regulation of CCN2 mRNA expression and promoter activity in activated hepatic stellate cells. J Cell Commun Signal. 2008;2(1-2):49-56

204. Li J, Ghazwani M, Zhang Y, Lu J, Li J, Fan J, et al. miR-122 regulates collagen production via targeting hepatic stellate cells and suppressing P4HA1 expression. J Hepatol. 2013;58(3):522-8.

205. Zeng C, Wang YL, Xie C, Sang Y, Li TJ, Zhang M, et al. Identification of a novel TGF- $\beta$-miR-122-fibronectin 1/serum response factor signaling cascade and its implication in hepatic fibrogenesis. Oncotarget. 2015;6(14):12224-33.

\section{Publisher's Note}

Springer Nature remains neutral with regard to jurisdictional claims in published maps and institutional affiliations.

Ready to submit your research? Choose BMC and benefit from:

- fast, convenient online submission

- thorough peer review by experienced researchers in your field

- rapid publication on acceptance

- support for research data, including large and complex data types

- gold Open Access which fosters wider collaboration and increased citations

- maximum visibility for your research: over $100 \mathrm{M}$ website views per year

At $\mathrm{BMC}$, research is always in progress.

Learn more biomedcentral.com/submissions 